\title{
C1q-independent activation of neutrophils by immunoglobulin M-coated surfaces.
}

\author{
Jonas Wetterö, Torbjörn Bengtsson and P Tengvall
}

\section{Linköping University Post Print}

N.B.: When citing this work, cite the original article.

This the authors' version of the final publication:

Jonas Wetterö, Torbjörn Bengtsson and $\mathrm{P}$ Tengvall, C1q-independent activation of neutrophils by immunoglobulin M-coated surfaces., 2001, Journal of Biomedical Materials Research, (57), 550-558.

http://dx.doi.org/

Copyright: Wiley

Postprint available at: Linköping University Electronic Press

http://urn.kb.se/resolve?urn=urn:nbn:se:liu:diva-25794 


\title{
C1q-independent activation of neutrophils
}

\section{by immunoglobulin M-coated surfaces ${ }^{1}$}

\author{
Jonas Wetterö $^{\mathrm{a}} \mathrm{b}_{*}$, Torbjörn Bengtsson ${ }^{\mathrm{b}}$ and Pentti Tengvall ${ }^{\mathrm{a}}$
}

${ }^{a}$ Laboratory of Applied Physics, Department of Physics and Measurement Technology, Linköping University, SE-581 83 Linköping, Sweden

${ }^{b}$ Division of Medical Microbiology, Department of Health and Environment, Faculty of Health Sciences, Linköping University, SE-581 85 Linköping, Sweden

*Corresponding author. Fax: +4613137568

E-mail address: jonwe@ifm.liu.se

Running Title: C1q-independent activation of neutrophils by IgM

${ }^{1}$ No benefit of any kind will be received either directly or indirectly by the authors. 
Abstract: Neutrophil granulocytes are known to rapidly adhere and undergo frustrated phagocytosis upon contact with immunoglobulin and/or complement protein opsonized artificial surfaces. In this study, we examined the relation between serum protein deposition and human neutrophil activation on hydrophobic glass and silicon model surfaces that were coated with immunoglobulin G or M (IgG/IgM), both initiators of the classical complement pathway. Protein adsorption from normal human serum (NHS) was quantified with nullellipsometry combined with antibody techniques. The neutrophil oxygen radical production was registered by luminol-amplified chemiluminescence (CL) and the morphology, as well as changes in the content of filamentous actin (F-actin), was documented by fluorescence microscopy. Complement factor 3 (C3) bound to both IgG- and IgM-coated surfaces, but surprisingly C1q was found only on IgG-coated surfaces. Both immunoglobulins triggered complement dependent neutrophil activation. However, CL and F-actin accumulation were found sensitive to the presence of C1q in serum only at the IgG-coated surface. We suggest that spontaneously adsorbed IgM activates the complement system and interacts with neutrophils by C1q-independent mechanisms.

Keywords: complement activation; immunoglobulins; actin cytoskeleton; neutrophil respiratory burst; protein adsorption 


\section{INTRODUCTION}

It is well established that artificial surfaces often activate both the cellular and humoral constituents of the inflammatory response upon contact with body fluids (reviewed by Tang and Eaton). ${ }^{1}$ Biomaterials may rapidly recruit leukocytes e.g. neutrophil granulocytes, a phenomenon likely mediated by cascade reactions following the spontaneous host plasma protein adsorption. The plasma protein layer composition is greatly influenced by relatively simple biomaterial characteristics, ${ }^{2-4}$ and different surface wettabilities provoke different behavior in adherent neutrophils. ${ }^{5-8}$ The neutrophil activation involves different antimicrobial mechanisms including oxygen radical production ${ }^{9,} 10$ and release of proteolytic enzymes, ${ }^{11}$ and excessive neutrophil activation at surfaces may potentially impair the host defense to subsequent infections. ${ }^{12}$

Two abundant and commonly adsorbed plasma proteins, IgG and fibrinogen, are both potent activators of adherent neutrophils, although by different mechanisms. ${ }^{13}$ The complement system opsonizes surfaces and takes active part in bacterial and cellular lysis and the immune complex clearance, $^{14}$ but its impact for acute inflammatory response to surfaces has been questioned. ${ }^{15}$ Nevertheless, the system is of importance for the maintenance of leukocyte adhesion to larger non-self surfaces, such as blood-contacting biomaterials in vitro. 16,17 The early studies on complement activation at the blood - material interface demonstrated a major role for the alternative activation pathway for the opsonization of in particular nucleophilic artificial surfaces, but the impact of the classical activation pathway is not yet well understood. However, it was recently demonstrated that the classical pathway is of importance also at nucleophilic surfaces ${ }^{18-20}$ and IgG, IgM, C1q and C3 have all been observed at the interface between blood and several artificial surfaces. ${ }^{18,} 21-23$ In the initiation part of the classical complement activation pathway, the $\mathrm{F}_{\mathrm{c}}$-parts of two surface-bound and adjacent IgG (not IgG I $_{4}$ or one IgM molecule interact with the globular heads of the C1q (11S-Protein)

molecule. 14, 24, 25 The soluble monomeric immunoglobulins, especially IgG, have only a weak affinity for C1q, but when surface-bound or aggregated immunoglobulins form two or three salt bridges with each globular head of C1q. 24,26 The C1q-binding site of IgG is located in the $\mathrm{C}_{\mathrm{H}} 2$ 
domain and IgM is suggested to bind $\mathrm{C} 1 \mathrm{q}$ in the $\mathrm{C}_{\mathrm{H}} 3$ domain. ${ }^{14} \mathrm{C} 1 \mathrm{r}$ and $\mathrm{C} 1 \mathrm{~s}$ then interacts with their binding sites located in the collagen region of the C1q molecule and the first classical pathway convertase is thereby assembled, and is now able to cleave and activate C4 and C2. These, in turn, form a C3-convertase, and cleaved C3 may form another C3-convertase that is common to all three known complement activation pathways. 25

The aim of the present study was to compare the effects of adsorption on two recognized classical complement activators, IgG and IgM, by means of subsequent spontaneous serum protein deposition and neutrophil inflammatory response. The experiments were performed using a surface model system that was previously described. ${ }^{6-8}$

\section{MATERIALS AND METHODS}

\section{Reagents, sera and buffers}

The reagents were of at least analytical grade and delivered from Sigma Chemical Co. (St. Louis, MO) unless otherwise stated. Normal human serum (NHS) was prepared from whole blood of several donors according to standard procedures, cooled on melting ice and immediately frozen below $70^{\circ} \mathrm{C}$. Pooled NHS was used to study protein adsorption and different single donor NHS were used in the neutrophil experiments. C1q-depleted serum and purified C1q were purchased from the Quidel Corp. (San Diego, CA, USA) and the complement cascade in the NHS was inhibited by heatinactivation for 30 minutes at $56^{\circ} \mathrm{C}$. Immobilization of immunoglobulins were performed in Phosphatebuffered saline (PBS; $10 \mathrm{mM}$ sodium hydrogen phosphate, $10 \mathrm{mM}$ potassium dihydrogen phosphate and $0.15 \mathrm{M}$ sodium chloride, $\mathrm{pH}$ 7.3). Studies on serum adsorption were performed in Veronalbuffered saline (5 mM 5,5'-dietylbarbituric acid, the corresponding sodium salt and $145 \mathrm{mM}$ sodium chloride, pH 7.4) supplemented with $0.15 \mathrm{mM} \mathrm{CaCl}_{2}$ and $0.5 \mathrm{mM} \mathrm{MgCl}_{2}\left(\mathrm{VBS}^{2+}\right)$. All buffers used in the protein adsorption experiments contained $0.25 \mathrm{mM}$ sodium azide. Isolated neutrophils (see below) were resuspended in Krebs-Ringer phosphate buffer supplemented with $10 \mathrm{mM}$ glucose, $1.5 \mathrm{mM}$ $\mathrm{MgSO}_{4}$ and $1.1 \mathrm{mM} \mathrm{CaCl}$, $\mathrm{pH} 7.3$ (KRG, free from sodium azide). 


\section{Isolation of neutrophils}

Peripheral human polymorphonuclear neutrophil granulocytes were isolated for each separate experiment from newly drawn heparinized whole blood of non-medicated volunteering donors (apparently healthy). In principle, the isolation procedure utilizes the methodology described by Böyum. 27 Only $\mathrm{Ca}^{2+}$-free buffers and suitable plastic devices were used during the separation. More specifically, whole blood was carefully layered on top of a separation liquid consisting of one part of Lymphoprep (Nycomed Pharma AS, Oslo, Norway) layered over four parts of Polymorphprep (Nycomed Pharma AS) and centrifuged for 40 minutes at $480 \times g$ at room temperature. The upper band containing mononuclear cells was discarded and the lower band containing neutrophils was harvested. The separation liquid was washed off through 10 minutes at $480 \mathrm{x} g$ in room tempered PBS. The erythrocyte contamination was then eliminated by brief hypotonic lysis in ice-cold distilled water followed by washing of the cells twice at $200 \mathrm{xg}$ at $4^{\circ} \mathrm{C}$ in KRG. The isolated cells showed excellent viability, low platelet contamination and were counted in a Coulter Counter ZM Channelyser 256 (Coulter-Electronics Ltd., Luton, UK) and kept on melting ice until pre-warming to $37^{\circ} \mathrm{C}$ immediately before the experiments.

\section{Surfaces}

Silicon wafers (Okmetic LMTD, Esbo, Finland) cleaved into 5 x $10 \mathrm{~mm}$ pieces in the (100) crystal direction, 76 x 26 mm Microscope Slides (Menzel-Gläser, Braunschweig, Germany, 72.2\% $\mathrm{SiO}_{2}$ ) or 40 x $8 \mathrm{~mm}$ glass test tubes (Assistent KHG, Sondheim-Rhön, Germany, approximately 75\% $\mathrm{SiO}_{2}$ ) were cleaned for 5 minutes at $80^{\circ} \mathrm{C}$ in distilled (Milli-Q) water, hydrogen peroxide (30\% v/v) and $\mathrm{NH}_{4} \mathrm{OH}(25 \% \mathrm{v} / \mathrm{v})$, 5:1:1 parts respectively. 28,29 The surfaces were then rinsed ten times in distilled water and incubated for another 5 minutes at $80^{\circ} \mathrm{C}$ in distilled water, hydrogen peroxide and hydrochloric acid (37\% v/v), 6:1:1 parts respectively. The $\mathrm{SiO}_{2}$-surfaces were thereby hydrated and accordingly hydrophilic (water/surface static contact angle, $\theta_{\mathrm{w}},<10^{\circ}$, estimated with a Ramé-Hart NRL Model 100 goniometer, USA). The hydrated surfaces were washed in distilled water and water was removed by rinsing in technically pure ethanol. The surfaces were then transferred to xylene (Merck, Darmstadt, Germany) and methylated during 5 minutes at room temperature in 1\% (v/v) 
dichlorodimethylsilane $\left(\mathrm{Cl}_{2}\left(\mathrm{CH}_{3}\right)_{2} \mathrm{Si}\right.$, DDS) in xylene. Finally, the hydrophobic $\left(\theta_{\mathrm{w}}>90^{\circ}\right)$ surfaces were rinsed in ethanol, xylene and, again, ethanol to remove traces of silane. The hydrophobic preparations were stored in ethanol and used within two weeks.

\section{Immunoglobulin adsorption}

The hydrophobic surfaces were washed in PBS and a monolayer of normal human IgG (prepared from pooled plasma, Gammaglobulin $165 \mathrm{mg} / \mathrm{ml}$, Pharmacia \& UpJohn, Stockholm, Sweden) or human IgM (from pooled serum, Sigma product no. I8260) was spontaneously adsorbed by over-night incubation in $0.1 \mathrm{mg} / \mathrm{ml}$ protein in PBS at room temperature. Immediately before experiments, non-adsorbed immunoglobulins were washed off by two gentle rinsings in PBS. The protein layer thickness' were 36 Ångströms ( $\left.\pm 2 \AA ; 1 \AA=1 \times 10^{-10} \mathrm{~m}\right)$ for IgG and $45 \AA$ ( $\pm 2 \AA$ ) for IgM. Since the IgM stock solution contained sodium azide (that potentially interferes with the CL method), 30,31 control experiments were carried out where the azide was removed. Small-volume dialysis of IgM in Slide-A-Lyzer (Pierce Chemical Company, Rockford, IL) cassettes (10,000 D MWCO membrane) was performed at $4^{\circ} \mathrm{C}$ against PBS with three buffer changes in between. Dialyzed and non-dialyzed IgM elicited similar neutrophil responses.

\section{Ellipsometry}

The protein adsorption during 5 minutes from serially diluted serum to hydrophobic silicon surfaces was analyzed by a combination of null-ellipsometry with antibody-techniques. After recording of the ellipsometric angles $\Delta$ and $\psi$ at the minimum intensity after reflection at the surface of elliptically polarized laser light (HeNe $\lambda=6328 \AA$ ) at $70^{\circ}$ angle of incidence, the surface film thickness was deduced using the McCrackin evaluation algorithm. ${ }^{32}$ The 5-minute serum adsorptions were performed at $37^{\circ} \mathrm{C}$ and the ellipsometric measurements performed in air (organic film refractive index $n_{\text {film }}=1.465$ ) using a Rudolf Research AutoEl III (NJ, USA). The $\mathrm{SiO}_{2}$ and DDS background

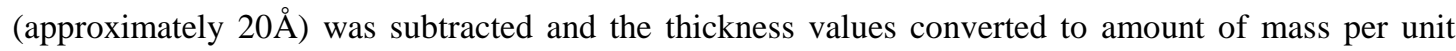
area according to de Feijter et al. ${ }^{33}$ The compositions of the adsorbed protein films were characterized by analysis of the thickening of the adsorbed layers after incubation of the serum-coated surfaces for 30 minutes in $\mathrm{VBS}^{2+}$ containing 1:50 (v/v) dilutions of specific polyclonal antibodies (immunoglobulin- 
fractions of polyclonal A 0062 rabbit anti-human C3c, A 0136 anti-C1q, A 0426 anti-IgM, specific for $\mu$-Chains and A 424 anti-IgG, specific for $\gamma$-Chains, Dakopatts, Glostrup, Denmark). A similar and more extensive study on protein adsorption during the activation of complement by IgG and IgM was recently published by Tengvall et al. ${ }^{34}$

\section{Chemiluminescence (CL)}

The intra- and extracellular generation of oxygen free radicals over time from neutrophils interacting with the methylated and protein coated glass tube surfaces was studied by luminolamplified chemiluminescence (CL) in a regularly calibrated six-channel Biolumat (LB 9505 C, Berthold Co., Wildbaden, Germany), essentially as described by Wetterö et al. $^{8}$ All measurements were performed at $37^{\circ} \mathrm{C}$ in $\mathrm{KRG}$, with the various sera added 5 minutes before horseradish peroxidase (4 U/ml), luminol (5-amino-2,3-dihydro-1,4-phtalazinedione, $50 \mu \mathrm{M})$ and cells $\left(1 \mathrm{x} 10^{6} / \mathrm{ml}\right)$ were introduced. The 5-minute NHS pre-incubation time was chosen because at this time period (i) classical pathway activation had started but not the alternative pathway; (ii) if the immunoglobulins binds C1q, then this protein is maximally accessible to react, as observed through the maximal deposition of antiC1q at this time period. ${ }^{34}$ The measurements were commonly performed for 30 or 60 minutes, but occasionally control experiments were continued for 3 hours. The experiments were performed at least in duplicate and the samples were analyzed in different channels for each new repeat. The C1qdepleted NHS was reconstituted with a high, but still physiologically relevant 25 dose of C1q (180 $\mu \mathrm{g} / \mathrm{ml}$ ) at least 3 hours before the serum was exposed to surfaces.

\section{Neutrophil morphology and quantification of F-actin}

The neutrophils were allowed to interact with methylated and immunoglobulin-coated glass slides placed at an approximate angle of $70^{\circ}$ relative to the horizontal plane in beakers containing sample buffers and sera. After 30 minutes of incubation, the slides with adherent cells were removed to a fixation buffer (4\% ice-cold paraformaldehyde in PBS) for 30 minutes. The fixed samples were then washed twice in PBS and stained for F-actin through 30 minutes of incubation in a solution containing $0.6 \mu \mathrm{g} / \mathrm{ml}$ bodipy phallacidin (Molecular Probes, Leiden, The Netherlands) and $100 \mu \mathrm{g} / \mathrm{ml}$ lysophosphatidylcholine in PBS at room temperature and protected from light. The stained samples 
were washed twice in PBS and mounted in Dako fluorescence mounting medium (Dakopatts, Glostrup, Denmark) containing anti-fade agent. The slides were studied and the fluorescence documented as positive color pictures with a Zeiss Axioscope equipped with a MC 100 microscope camera (Carl Zeiss, Oberkochen, Germany). The mounted positive images were scanned using a Nikon (Japan) LS2000 Scanner and Nikon Scan 2.2 software. All editing of the scanned images was performed using the Canvas 5.0.1 software (Deneba Systems, Inc., Miami, FL). The F-actin content in single, adherent neutrophils was quantified by registration of the fluorescence in a cytofluorometer. ${ }^{35}$ In brief, cells were observed and individual neutrophils of varying morphology selected in the light-microscopy mode of a Leitz MPV II microscope photometer connected to a computer system. For each sample, 30 or 50 individual cells per slide were excited for $<0.8$ s and the fluorescence recorded. The background fluorescence values were routinely subtracted.

\section{Data analysis}

The data were assumed normally distributed and the results are presented as arithmetic means \pm standard errors of the means (SEM). The statistical evaluation was performed using the paired (if nothing else is mentioned) or non-paired, two-tailed Student's t-test (Microsoft Excel 97). Three levels of significance were used $(p<0.05,0.01$ or 0.001$)$.

\section{RESULTS}

\section{Protein Adsorption}

Both IgG- and IgM-coated hydrophobic silicon surfaces acquired a significant deposition of serum proteins after 5 minutes of exposure to diluted NHS (Fig. 1A) and the immunoglobulin-coated surfaces bound their respective specific polyclonal antibody at low serum concentrations (not shown) indicating that the C1q- and $\mathrm{F}_{\mathrm{c}}$-reptor binding $\mathrm{F}_{\mathrm{c}}$-regions of the pre-adsorbed immunoglobulins were at least initially accessible to both humoral and cellular interactions. The binding of the specific antibodies against adsorbed complement proteins varied with the NHS dilution (Fig. 1B). Anti-C3c 
bound to both IgG- and IgM-coated surfaces after 5 minutes of incubation when the NHS concentration exceeded $1 \%$. C1q was detectable only at the IgG-coated surface for NHS concentrations ranging between $1 \%$ to $10 \%$. This C1q-deposition at IgG monolayers was inhibited when $\mathrm{Ca}^{2+}$ in $\mathrm{NHS}$ was

chelated with EGTA and when C1q-depleted serum was used instead of NHS. ${ }^{34}$ Surprisingly, anti-C1q did not bind to serum layers at any dilution on IgM-coated surfaces. In order to investigate if the absence of C1q on immobilized IgM could influence the activation of neutrophils, further experiments were performed with neutrophils that interacted with similarly treated glass surfaces.

\section{Neutrophil respiratory burst}

In a previous study we showed that the oxygen radical production from neutrophils that interact with clean methylated hydrophobic surfaces in KRG was amplified by approximately 15\% after coating with IgG. ${ }^{8}$ Upon interaction with the IgM-coated surfaces, the CL was instead lowered by 52\% ( $\mathrm{p}<0.001)$. The CL response at the non-coated hydrophobic surface was lowered by approximately $20 \%$ in the presence of $5 \%$ NHS in the medium during the experiments. When the commercial C1q-depleted serum was reconstituted with $\mathrm{C} 1 \mathrm{q}$, it induced effects similar to those obtained with the NHS. C1q-depleted serum, however, showed only 37\% of the CL activity compared to C1q-repleted serum $(\mathrm{p}<0.01)$ at non-coated surfaces. As previously reported, ${ }^{8}$ the neutrophil radical response was again very potent when heat-inactivated serum was exposed to the non-coated hydrophobic surface.

When the IgM-coated surfaces were exposed to $5 \%$ NHS 5 minutes prior to the addition of cells, an amplification by 344\% ( $p<0.05$, compared with the IgM-surfaces without NHS exposure) of the neutrophil respiratory burst activity was observed. The response was slow with a single peak after 15-25 minutes, and approached the base levels within an hour (Fig. 2A). The IgM/NHS-triggered neutrophil response was reduced by 61\% $(p<0.05)$ when heat-inactivated NHS was used instead. IgMcoated surfaces that were incubated in C1q-depleted or reconstituted sera showed almost identical CL responses, indicating that $\mathrm{C} 1 \mathrm{q}$ was not essential for the IgM-triggered response (Fig. 2B). Control experiments with IgM-coated hydrophilic tubes showed no difference in the neutrophil radical generation between non-heated NHS and heat-inactivated serum, indicating that the above response depended on the adsorbed IgM (proteins are easily displaced on hydrophilic surfaces). ${ }^{2}$ IgG-coated 
hydrophobic surfaces induced a massive neutrophil oxygen radical generation after NHS was exposed to the surface. ${ }^{8}$ The response was biphasic with peaks after approximately 10 and 20 minutes (essentially like the reconstituted serum in Fig. 2C) and sensitive to the presence of $\mathrm{C} 1 \mathrm{q}$ in serum. The second peak disappeared when the NHS was heat-inactivated or depleted on C3. Blocking of neutrophil $\mathrm{F}_{\mathrm{c}}$ - and complement receptors was performed prior to contact with the serum-exposed IgGcoated surfaces. Only minor effects were observed when monoclonal antibodies specific for the receptors were used, suggesting that C1q, IgG and C3 triggered the CL in synergy. However, approximately $75 \%$ of the CL response could be quenched when the complement receptor 3 was blocked with an inhibitory peptide. ${ }^{8}$

The integrated CL response from the neutrophils after 30 minutes of contact with complement-opsonized IgG-coated surfaces was clearly lower $(38 \%$; $p<0.01)$ when C1q was absent (Fig. 3, left). Both the primary and secondary peaks were reduced (Fig. 2C). However, the neutrophil respiratory burst activity on IgM-surfaces was more or less insensitive to the presence of C1q for 30 minutes (Fig. 3, right) or 1-3 hours of measurement (not shown). In order to further characterize the CL response, neutrophils that interacted with IgG- or IgM-surfaces were exposed to a second stimulus, 0.1 $\mu \mathrm{M}$ of the chemotactic peptide formyl-methionyl-leucyl-phenylalanine (fMet-Leu-Phe) that was added after 30 minutes of cell - surface interaction. We observed then that fMet-Leu-Phe induced a CL response on both surfaces and the responsiveness to fMet-Leu-Phe was higher in serum environments (not shown).

\section{Neutrophil adhesion and cytoskeletal F-actin}

Several studies have shown a relationship between occupation of phagocytosis and adhesion receptors, reorganization of the actin cytoskeleton and activation of the NADPH-oxidase in neutrophils. ${ }^{36,} 37$ We found that the NHS-coated IgM-surfaces attracted only half the number of neutrophils, compared to IgG/NHS-surfaces (Table 1). No significant differences regarding the number of adherent cells were registered in the absence or presence of C1q in serum, on either IgG- or IgMsurfaces. On serum-opsonized IgG-coated surfaces, neutrophils exhibited an extensive spreading including accumulation of F-actin in moving peripheral lamellipodia and focal adhesion points (Fig. 
4A), and when the serum was depleted on C1q the spreading and actin polymerization was slightly reduced (Fig. 4B, Fig. 5). Cells that adhered to serum-opsonized IgM-surfaces, with or without C1q, displayed less pronounced spreading (Fig. 4C) and F-actin accumulation than in lamellipods and focal contacts on IgG-coated surfaces (Fig. 5).

\section{DISCUSSION}

The present study indicates that adsorbed IgG- and IgM-monolayers both activate the complement system, the former dependent and the latter independent on C1q. Thus, the C3 surfaceopsonizations occur through partly different mechanisms. The difference is surprising since it is expected that IgG-coated surfaces are less C1q-dependent due to known direct covalent associations between IgG and C3.38, 39

The radical production induced by NHS was higher on IgG- than on IgM-coated surfaces since neutrophils, at least initially, may have interacted with both surface-localized immunoglobulins and complement proteins, among them $\mathrm{C} 1 \mathrm{q}$ and C3. In contrast to IgG, IgM is not a ligand for neutrophil $\mathrm{F}_{\mathrm{c}}$-receptors $40-42$ and consequently IgM is a weak opsonin. Furthermore, IgG, C1q and C3 may activate both non-adherent and adherent neutrophils either through independent or synergetic stimulation of $\mathrm{F}_{\mathrm{C}^{-}}$and complement receptors. ${ }^{7,}$, , 37, 43-51 It is therefore reasonable to assume that blood cells interact with immunoglobulin-fixed C1q, since the collagen-like region of C1q is known to interact with cell-surface receptors and the globular heads of C1q bind to IgG or IgM. The total neutrophil CL response on IgG/NHS-surfaces was affected when C1q was depleted from NHS, indicating that the classical activation pathway was involved. Hence, we suggest that the initial phase of the biphasic ${ }^{8} \mathrm{CL}$ response on IgG/NHS-surfaces depend on $\mathrm{F}_{\mathrm{c}^{-}}$and, possibly, C1q-receptor stimulation by surface-denatured IgG and fixed C1q since: (i) this early part of the CL profile was not observed on IgM/NHS-coated surfaces; (ii) the first part was relatively insensitive to heat-inactivation

of $\mathrm{NHS}^{8}$ (iii) the stimulation corresponded in time roughly with the response triggered by IgG in serum-free media; and; (iv) neutrophils in KRG containing NHS were more activable by a second 
fMLP-stimulation than without NHS, suggesting that NHS enhances the oxygen radical production induced by ligation of cell surface receptors (e.g. $\mathrm{F}_{\mathrm{c}}$-receptors). The second phase of the CL response on the IgG/NHS-surfaces was probably complement-receptor dependent, as demonstrated by the heatinactivated serum and by the use of various complement-depleted sera. In support for this, the entire CL response on IgM/NHS-surfaces seemed to be triggered by complement-dependent factors since the heat-inactivation markedly decreased the response and the CL correlated in time with the complementdependent latter part on the IgG/NHS-surface.

The actin filament system and associated receptors become activated during the contact with artificial materials. $36,52,53$ Others and we have shown previously that the complement-triggered neutrophil radical response depends on a dynamic actin cytoskeleton. 7,8 Both the phagocytosis process and the regulation of the NADPH-oxidase require the action of the actin cytoskeleton, which may explain the extensive actin polymerization obtained on the IgG/NHS-surfaces. The C1q-triggered neutrophil oxidative response is especially potent when $\mathrm{C} 1 \mathrm{q}$ is surface-bound 45 and $\mathrm{C} 1 \mathrm{q}$ also enhances the phagocytosis process. ${ }^{47}$ The obvious conclusion in the present study is that IgG-coated, but not IgM-coated, surfaces bind and expose C1q during the early activation phase, thereby presenting C1q to neutrophils at the blood-material interface.

IgG is much more abundant in plasma than IgM (8-17 versus $0.05-2 \mathrm{mg} / \mathrm{ml})^{3}$ and as it is a smaller molecule it diffuses more rapidly to surfaces. On the other hand, rapidly adsorbed proteins can be covered by other proteins or be replaced, thereby becoming less accessible to the later arriving platelets and leukocytes. Consequently, a potential role for the large and slowly diffusing acute-phase IgM molecule during biomaterial-related neutrophil activation is possible. In conclusion, both IgMand IgG-coated hydrophobic surfaces become readily opsonized by C3, the former in a C1qindependent manner. This may affect the regulation of the neutrophil inflammatory response at artificial surfaces in contact with body fluids.

Financial support came from the Biocompatible Materials Program (Swedish National Foundation for Strategic Research, SSF), the Swedish Medical Research Council (grant number 71X12668) and the local Linköping Lion Foundation (Forskningsfond mot folksjukdomar). Agneta 
Askendal (Laboratory of Applied Physics) is acknowledged for assistance with the ellipsometric analyses. We also thank Anna Berg (Department of Cell Biology) for help with scanning equipment. 


\section{REFERENCES}

1 Tang L, Eaton JW. Inflammatory responses to biomaterials. Am J Clin Pathol 1995;103:46671.

2 Vroman L, Adams AL. Identification of rapid changes at plasma-solid interfaces. J Biomed Mater Res 1969;3:43-67.

3 Andrade JD, Hlady V. Plasma protein adsorption: the big twelve. Ann NY Acad Sci $1987 ; 516: 158-72$.

4 Collier TO, Jenney CR, DeFife KM, Anderson JM. Protein adsorption on chemically modified surfaces. Biomed Sci Instrumentation 1997;33:178-83.

5 Tomczok J, Sliwa-Tomczok W, Klein CL, van Kooten TG, Kirkpatrick CJ. Biomaterialinduced alterations of human neutrophils under fluid shear stress: scanning electron microscopical study in vitro. Biomaterials 1996;17:1359-67.

6 Karlsson C, Nygren H, Braide M. Exposure of blood to biomaterial surfaces liberates substances that activate polymorphonuclear granulocytes. J Lab Clin Med 1996;128:496-505.

7 Liu L, Elwing H, Karlsson A, Nimeri G, Dahlgren C. Surface-related triggering of the neutrophil respiratory burst. Characterization of the response induced by IgG adsorbed to hydrophilic and hydrophobic glass surfaces. Clin Exp Immunol 1997;109:204-10.

8 Wetterö J, Bengtsson T, Tengvall P. Complement activation on immunoglobulin G-coated hydrophobic surfaces enhances the release of oxygen radicals from neutrophils through an actin-dependent mechanism. J Biomed Mater Res 2000;51:742-51.

9 Leto TL. The respiratory burst oxidase. In: Gallin, JI and Snyderman, R, eds. Inflammation: Basic principles and clinical correlates. Philadelphia: Lippincott Williams \& Wilkins, 1999. p. 769-786.

Babior BM. NADPH oxidase: an update. Blood 1999;93:1464-76.

Elsbach P, Weiss J, Levy O. Oxygen-independent antimicrobial systems of phagocytes. In:

Gallin, JI and Snyderman, R, eds. Inflammation: Basic principles and clinical correlates. Philadelphia: Lippincott Williams \& Wilkins, 1999. p. 801-817. 
Kaplan SS, Basford RE, Jeong MH, Simmons RL. Biomaterial-neutrophil interactions: dysregulation of oxidative functions of fresh neutrophils induced by prior neutrophilbiomaterial interaction. J Biomed Mater Res 1996;30:67-75.

De La Cruz C, Haimovich B, Greco RS. Immobilized IgG and fibrinogen differentially affect the cytoskeletal organization and bactericidal function of adherent neutrophils. J Surg Res 1998;80:28-34.

Cooper NR. Biology of the complement system. In: Gallin, JI and Snyderman, R, eds. Inflammation: Basic Principles and Clinical Correlates. Philadelphia: Lippincott Williams \& Wilkins, 1999. p. 281-315.

Tang L, Eaton JW. Fibrin(ogen) mediates acute inflammatory responses to biomaterials. J Exp Med 1993;178:2147-56.

Kao WJ, Sapatnekar S, Hiltner A, Anderson JM. Complement-mediated leukocyte adhesion on poly(etherurethane ureas) under shear stress in vitro. J Biomed Mater Res 1996;32:99-109. Gorbet MB, Yeo EL, Sefton MV. Flow cytometric study of in vitro neutrophil activation by biomaterials. J Biomed Mater Res 1999;44:289-97.

Tengvall P, Askendal A, Lundström I. Complement activation by 3-mercapto-1,2-propanediol immobilized on gold surfaces. Biomaterials 1996;17:1001-7.

Lhotta K, Wurzner R, Kronenberg F, Oppermann M, Konig P. Rapid activation of the complement system by cuprophane depends on complement component C4. Kidney Int 1998;53:1044-51.

Wetterö J, Askendal A, Bengtsson T, Tengvall P. On the binding of complement to solid artificial surfaces in vitro. Biomaterials 2001;Submitted after revision. Boisson-Vidal C, Jozefonvicz J, Brash JL. Interactions of proteins in human plasma with modified polystyrene resins. J Biomed Mater Res 1991;25:67-84.

Babensee JE, Cornelius RM, Brash JL, Sefton MV. Immunoblot analysis of proteins associated with HEMA-MMA microcapsules: human serum proteins in vitro and rat proteins following implantation. Biomaterials 1998;19:839-49.

Panichi V, Casarosa L, Gattai V, Bianchi AM, Andreini B, Migliori M, De Pietro S, Giovannini L, Palla R. Protein layer on hemodialysis membranes: a new immunohistochemistry technique. Int J Artif Organs 1995;18:305-8. 
Borsos T. Immune complex mediated activation of the classical complement pathway. Behring Institute Mitteilungen 1989;93-101. Hänsch, GM, eds. The complement system. Heidelberg: Springer Verlag Berlin, 1998. p. 123.

Kishore U, Reid KB. Modular organization of proteins containing C1q-like globular domain. Immunopharmacology 1999;42:15-21.

Böyum A. Isolation of mononuclear cells and granulocytes from human blood. Isolation of monuclear cells by one centrifugation, and of granulocytes by combining centrifugation and sedimentation at $1 \mathrm{~g}$. Scandinavian Journal Of Clinical And Laboratory Investigation. Supplement 1968;97:77-89.

Kern W, Puotinen DA. Cleaning solutions based on hydrogen peroxide for use in silicon semiconductor technology. RCA Rev 1970;187-206.

Peters DA, Deckert CA. Removal of photoresist film residues from wafer surfaces. J Elechtrochem Soc 1979;883-886.

Wymann MP, von Tscharner V, Deranleau DA, Baggiolini M. Chemiluminescence detection of $\mathrm{H} 2 \mathrm{O} 2$ produced by human neutrophils during the respiratory burst. Anal Biochem $1987 ; 165: 371-8$

31 Ginsburg I, Misgav R, Gibbs DF, Varani J, Kohen R. Chemiluminescence in activated human neutrophils: role of buffers and scavengers. Inflammation 1993;17:227-43. McCrackin FL. (1969) in NBS Technical Note 479, Washington DC. de Feijter JA, Benjamins J, Veer FA. Ellipsometry as a tool to study the adsorption of synthetic and biopolymers at the air-water interface. Biopolymers 1978;17:1759-73.

Tengvall P, Askendal A, Lundström I. Ellipsometric in vitro studies on the activation of complement by human immunoglobulin $\mathrm{M}$ after adsorption to methylated silicon. Colloids and surfaces B; Biointerfaces 2001;20:51-62. phosphatidylinositol 4,5-bisphosphate is not an initiating factor for actin assembly in human neutrophils. J Biol Chem 1988;263:17385-9. 

Actin dynamics in human neutrophils during adhesion and phagocytosis is controlled by changes in intracellular free calcium. European J Cell Biol 1993;62:49-58.

Zhou MJ, Brown EJ. CR3 (Mac-1, alpha M beta 2, CD11b/CD18) and Fc gamma RIII cooperate in generation of a neutrophil respiratory burst: requirement for Fc gamma RIII and tyrosine phosphorylation. J Cell Biol 1994;125:1407-16.

Gadd KJ, Reid KB. The binding of complement component C3 to antibody-antigen aggregates after activation of the alternative pathway in human serum. Biochem J 1981;195:471-80. Sahu A, Pangburn MK. Covalent attachment of human complement C3 to IgG. Identification of the amino acid residue involved in ester linkage formation. J Biol Chem 1994;269:289979002.

Cordier G, Samarut C, Revillard JP. Distinct functions of surface receptors in the induction of neutrophil-mediated cytotoxicity. Annales D Immunologie 1981;132D:3-14.

Kay AB, Walsh GM. Chemotactic factor-induced enhancement of the binding of human immunoglobulin classes and subclasses to neutrophils and eosinophils. Clin Exp Immunol $1984 ; 57: 729-34$

Walsh GM, Kay AB. Binding of immunoglobulin classes and subclasses to human neutrophils and eosinophils. Clin Exp Immunol 1986;63:466-72.

Goldstein IM, Kaplan HB, Radin A, Frosch M. Independent effects of IgG and complement upon human polymorphonuclear leukocyte function. J Immunol 1976;117:1282-7.

Tenner AJ, Cooper NR. Identification of types of cells in human peripheral blood that bind C1q. J Immunol 1981;126:1174-9.

Tenner AJ, Cooper NR. Stimulation of a human polymorphonuclear leukocyte oxidative response by the C1q subunit of the first complement component. J Immunol 1982;128:254752.

Chatham WW, Heck LW, Blackburn WDJ. Ligand-dependent release of active neutrophil collagenase. Arthritis Rheum 1990;33:228-34.

Guan EN, Burgess WH, Robinson SL, Goodman EB, McTigue KJ, Tenner AJ. Phagocytic cell molecules that bind the collagen-like region of C1q. Involvement in the C1q-mediated enhancement of phagocytosis. J Biol Chem 1991;266:20345-55. 
48 Chatham WW, Blackburn WD Jr. Fixation of C3 to IgG attenuates neutrophil $\mathrm{HOCl}$ generation and collagenase activation. J Immunol 1993;151:949-58.

49 Chatham WW, Turkiewicz A, Blackburn WDJ. Determinants of neutrophil HOCl generation: ligand-dependent responses and the role of surface adhesion. J Leukocyte Biol 1994;56:65460.

50 Katz DA, Haimovich B, Greco RS. Fc gamma RII, Fc gamma RIII, and CD18 receptors mediate in part neutrophil activation on a plasma coated expanded polytetrafluoroethylene surface. Surgery 1995;118:154-61.

51 Goodman EB, Anderson DC, Tenner AJ. C1q triggers neutrophil superoxide production by a unique CD18-dependent mechanism. J Leukocyte Biol 1995;58:168-76.

52 Wakabayashi Y, Sasaki J, Fujita H, Fujimoto K, Morita I, Murota S, Kawaguchi H. Effects of surface modification of materials on human neutrophil activation. Biochim Biophys Acta 1995;1243:521-8.

53 Tabor B, Geissler B, Odell R, Schmidt B, Blumenstein M, Schindhelm K. Dialysis neutropenia: the role of the cytoskeleton. Kidney Int 1998;53:783-9. 


\section{CAPTIONS}

Table 1. Characterization and quantification of adherent neutrophils on serum-opsonized immunoglobulin G or M (IgG/IgM) pre-coated hydrophobic glass slides. The C1q-dependency for the adhesion was investigated. The cells were counted in at least 10 separate microscopy views (original magnification $\mathrm{x}$ 400) on each slide, and prepared in duplicate for 3 donors. For further details regarding the slides, see captions Fig. 4-5.

\section{Figure 1.}

(A) Deposition of normal human serum (NHS) at various concentrations, after 5 minutes, at $37^{\circ} \mathrm{C}$, onto surfaces that were pre-coated with a monolayer of immunoglobulin G (IgG) or M (IgM). The NHS was diluted in $\mathrm{VBS}^{2+}$ and rinsed with pre-warmed buffer before the ellipsometric measurement $(\mathrm{n}=5 ; \pm$ SEM).

(B) Deposition of specific polyclonal anti-C1q or anti-C3c to surfaces in (A).

Figure 2. Chemiluminescence profiles for IgG- and IgM pre-coated surfaces that were exposed/not exposed to $5 \%$ serum for 5 minutes prior to the introduction of neutrophils $\left(1 \times 10^{6} / \mathrm{ml}\right)$. The illustrations in A-C shows examples from different donors on the total generation of oxygen free radicals from isolated neutrophils interacting with the immunoglobulin-coated hydrophobic glass surfaces at $37^{\circ} \mathrm{C}$ in $\mathrm{KRG}$ buffer, with or without native or C1q-depleted serum added 5 minutes before the cells. The counts per minute (CPM) of chemiluminescence were recorded in a Biolumat in presence of luminol $(50 \mu \mathrm{M})$ and extra peroxidase $(4 \mathrm{U} / \mathrm{ml})$. The response at non-coated hydrophobic surfaces is described in the text and elsewhere ${ }^{8}$.

(A) Immunoglobulin M (IgM) pre-coated surfaces were exposed or not exposed to normal human serum (NHS). In control experiments the complement in the NHS was inhibited by heating to $56^{\circ} \mathrm{C}$ for 30 minutes. 
(B) IgM-coated surfaces exposed to NHS depleted on complement factor $1 \mathrm{q}(\mathrm{C} 1 \mathrm{q})$. In control experiments, the depleted serum was reconstituted with $180 \mu \mathrm{g} / \mathrm{ml} \mathrm{C1q}$. Note the relative insensitivity to C1q for the radical generation.

(C) As (B) but IgG-coated surfaces.

Figure 3. Neutrophil respiratory burst in serum-opsonized hydrophobic glass tubes pre-coated with immunoglobulin G (IgG) or M (IgM). The figures show the 30-minute integrated chemiluminescence values generated from $1 \times 10^{6} / \mathrm{ml}$ neutrophils in the presence of $50 \mu \mathrm{M}$ luminol and $4 \mathrm{U} / \mathrm{ml}$ horseradish peroxidase, with or without 5\% normal human serum (NHS) depleted on complement factor 1q (C1q). In control experiments, the depleted serum was reconstituted with $180 \mu \mathrm{g} / \mathrm{ml} \mathrm{C1q}$. The experiments were performed at least in duplicate with neutrophils from 8 separate donors in a six-channel Biolumat at $37^{\circ} \mathrm{C}$ in $\mathrm{KRG}$ buffer. (CPM = counts per minute, bars illustrates the SEM).

Figure 4. Neutrophil morphology displayed after 30 minutes of interaction with immunoglobulin precoated hydrophobic glass slides that were exposed to different sera for 5 minutes. The neutrophils were subsequently fixed in 4\% paraformaldehyde, permeabilized with lysophosphatidylcholine and the filamentous actin (F-actin) was stained with bodipy-phallacidin. Positive images were documented using a Zeiss Axioscope and an MC 100 microscope camera, developed at ASA 3200 and scanned. Images A-C were treated identically during edition. Original magnification x 630.

(A) Immunoglobulin G coated surfaces exposed to 3\% complement factor 1q (C1q) depleted normal human serum (NHS) that was reconstituted with $180 \mu \mathrm{g} / \mathrm{ml} \mathrm{C1q}$, followed by the addition of neutrophils.

(B) As in (A) but with C1q-depleted serum.

(C) Immunoglobulin M coated surfaces exposed to 3\% C1q-depleted NHS that was reconstituted with $180 \mu \mathrm{g} / \mathrm{ml} \mathrm{C1q.} \mathrm{The} \mathrm{morphology} \mathrm{was} \mathrm{similar} \mathrm{on} \mathrm{surfaces} \mathrm{exposed} \mathrm{to} \mathrm{C1q-depleted} \mathrm{serum.}$

Figure 5. Quantification of the filamentous actin (F-actin) in individual neutrophils that adhered to serum-opsonized (3\%) immunoglobulin M (IgM) or G (IgG) coated methylated glass slides. The neutrophils were fixed after 30 minutes (4\% paraformaldehyde), permeabilized (lysophosphatidylcholine) and the F-actin stained with bodipy-phallacidin. The results demonstrate the 
effect following reconstitution with $180 \mu \mathrm{g} / \mathrm{ml}$ complement factor (C1q) into the C1q-depleted normal human serum. The zero-level indicates fluorescence after interaction with C1q-depleted serum. All experiments were performed in duplicate and 30 or 50 cells were analyzed for each slide. The results are averaged from 4 separate donors and the bars indicate the SEM. The change in fluorescence on IgG-, but not on IgM-surfaces, after the C1q-reconstitution was significant ( $p<0.05$; non-paired). 
TABLE 1

\begin{tabular}{l|cl}
\hline \multicolumn{1}{c|}{ Surfaces } & $\begin{array}{c}\text { Relative number } \\
\text { of neutrophils }\end{array}$ & \multicolumn{1}{c}{ Morphology } \\
\hline $\begin{array}{l}\text { IgG-coated + C1q-depleted } \\
\text { serum reconstituted with C1q }\end{array}$ & $223 \%$ & $\begin{array}{l}\text { Very spread, perifer accumulation of F- } \\
\text { actin (Fig. 4A) }\end{array}$ \\
$\begin{array}{l}\text { IgG-coated + C1q-depleted } \\
\text { serum }\end{array}$ & $256 \%$ & $\begin{array}{l}\text { Most cells show extensive spreading but a } \\
\text { little less pronounced F-actin } \\
\text { accumulation than above (Fig. 4B) }\end{array}$ \\
$\begin{array}{l}\text { IgM-coated + C1q-depleted } \\
\text { serum reconstituted with C1q }\end{array}$ & $128 \%$ & $\begin{array}{l}\text { Moderately spread (Fig. 4C) } \\
\text { IgM-coated + C1q-depleted } \\
\text { serum }\end{array}$ \\
& (=CONTROL) & Moderately spread (Fig. 4C) \\
\hline
\end{tabular}


Figure 1
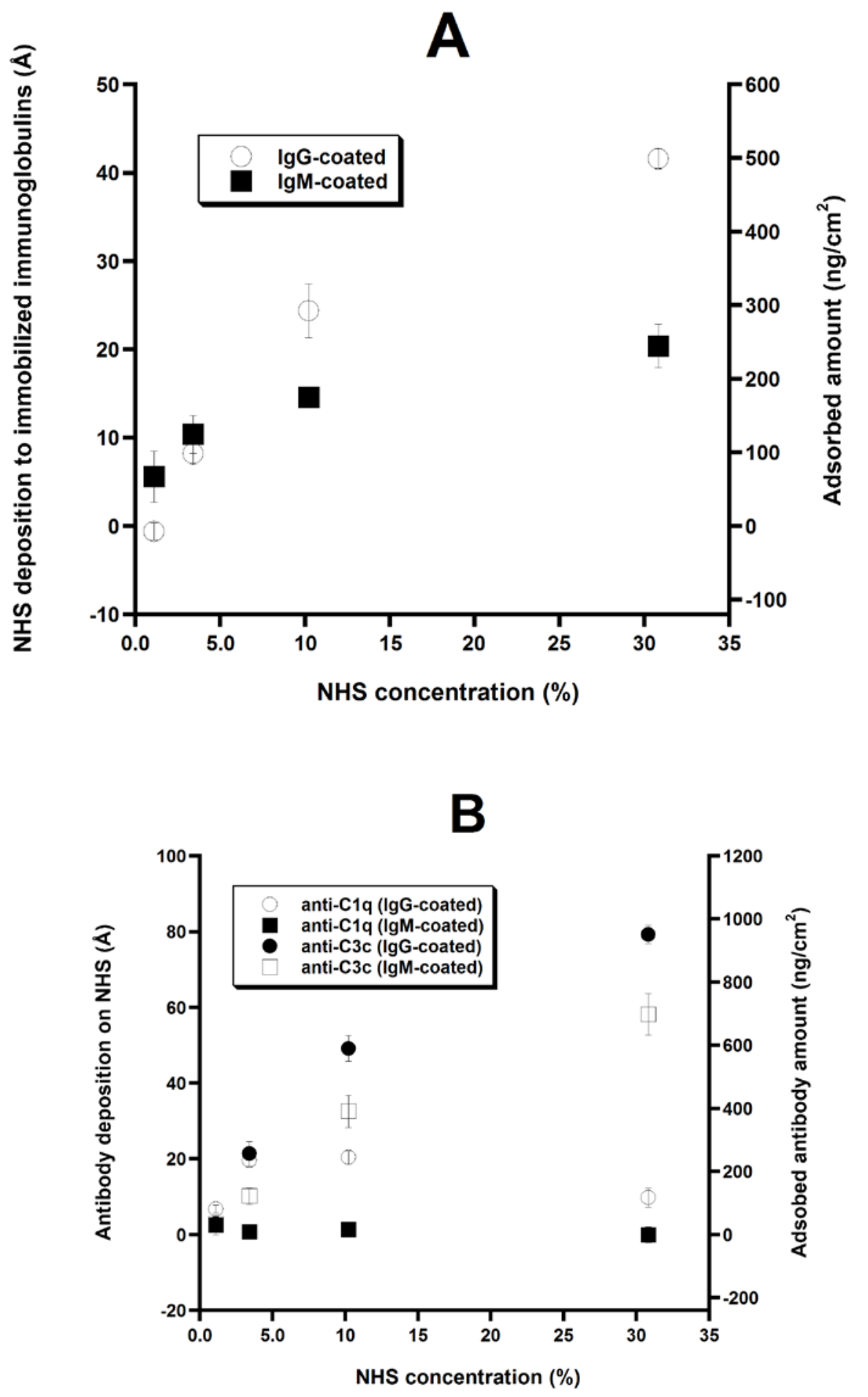


\section{Figure2}

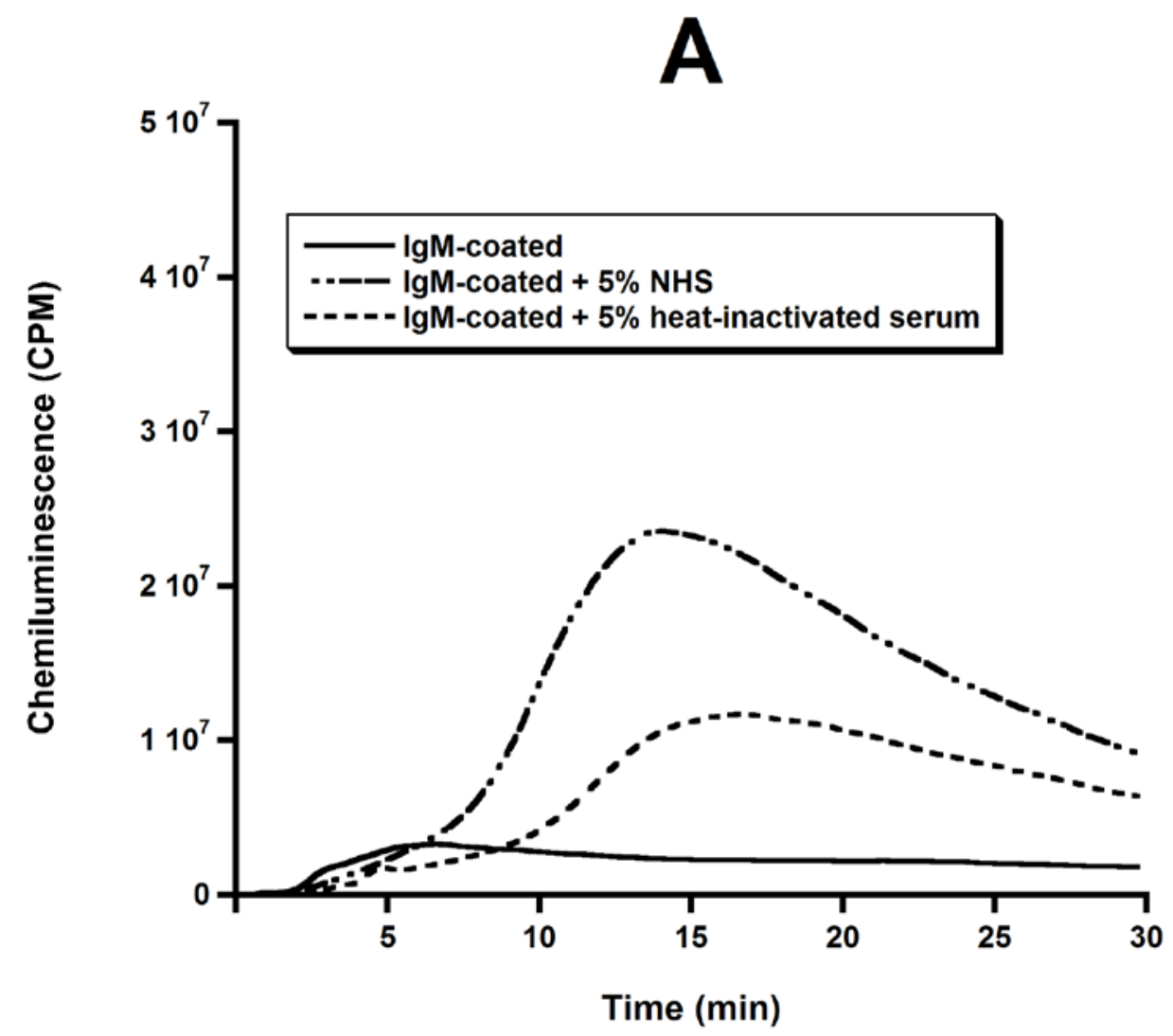




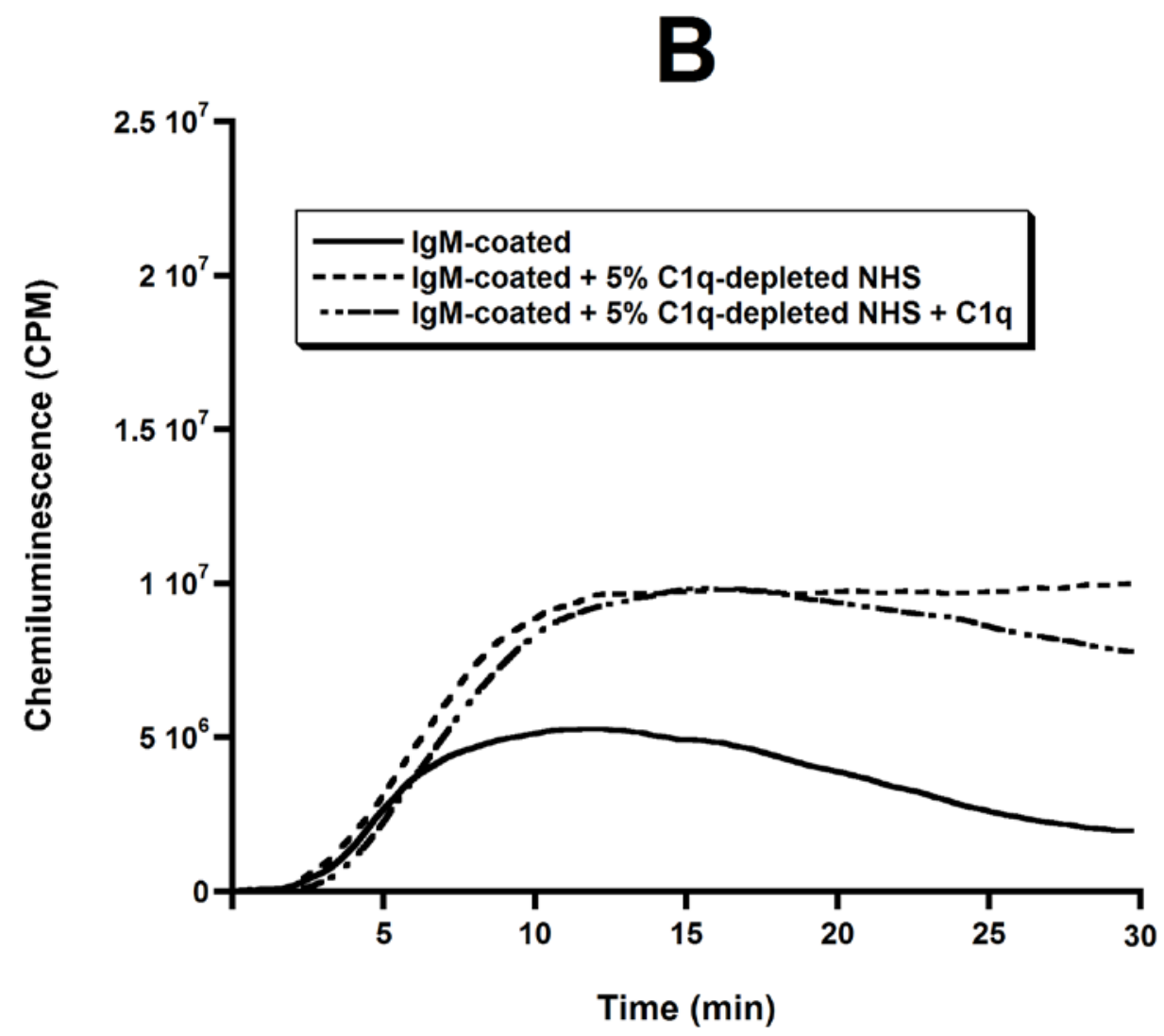




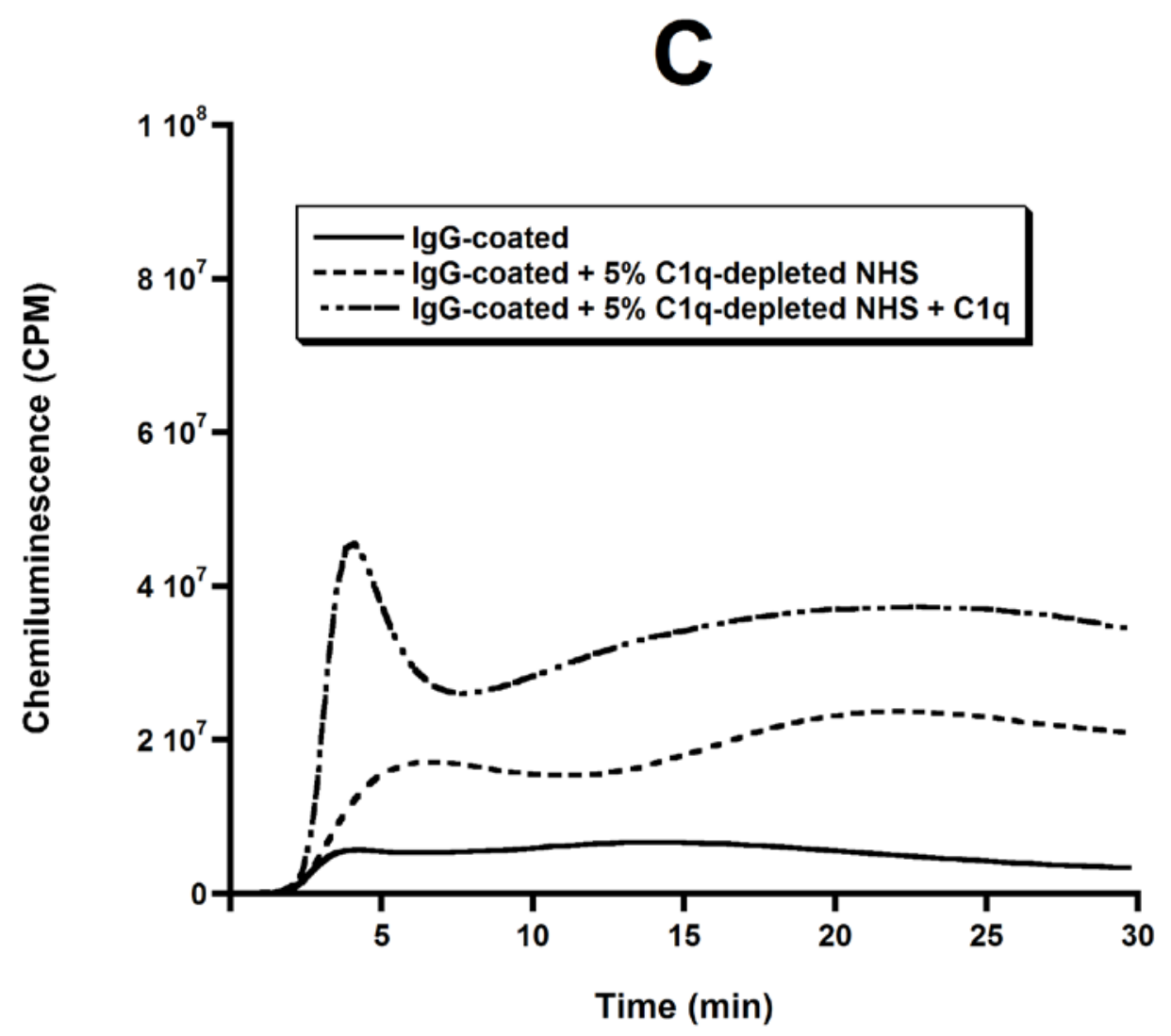


Figure 3

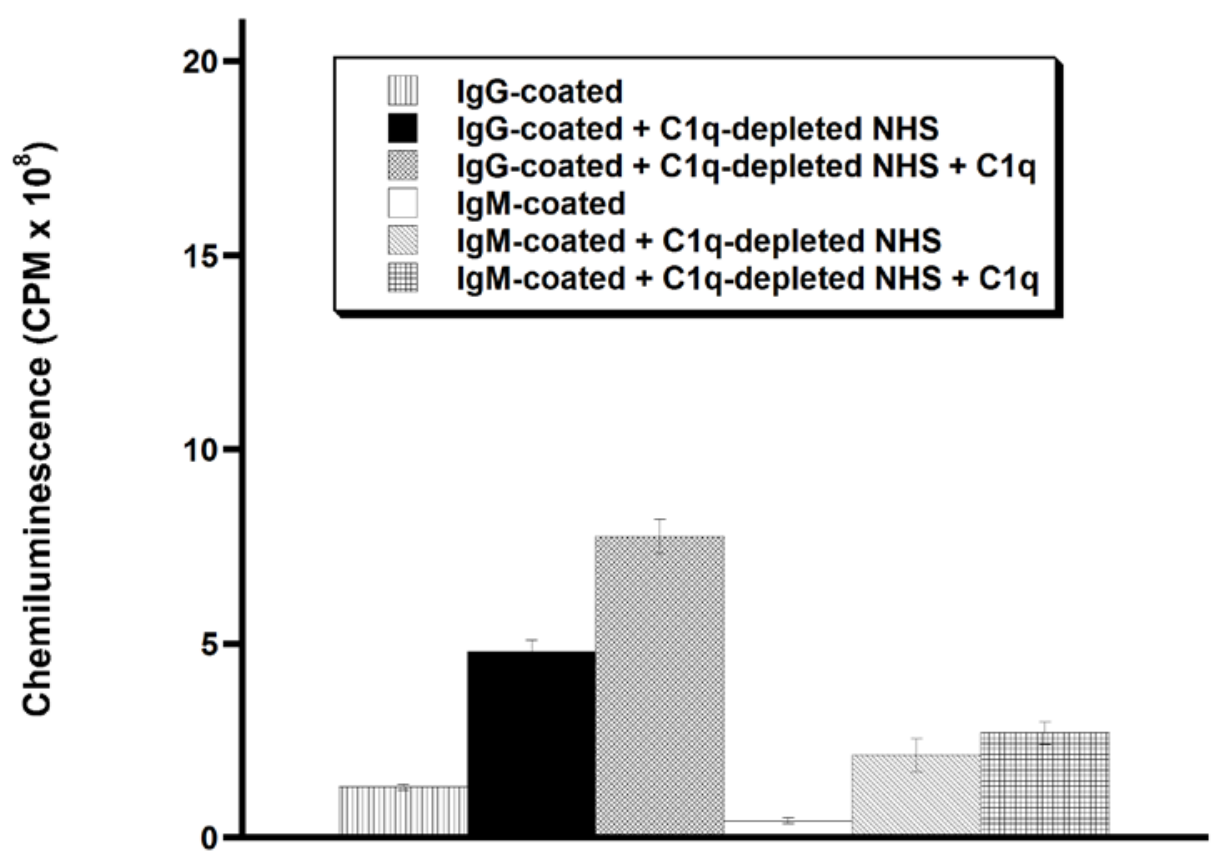


Figure 4
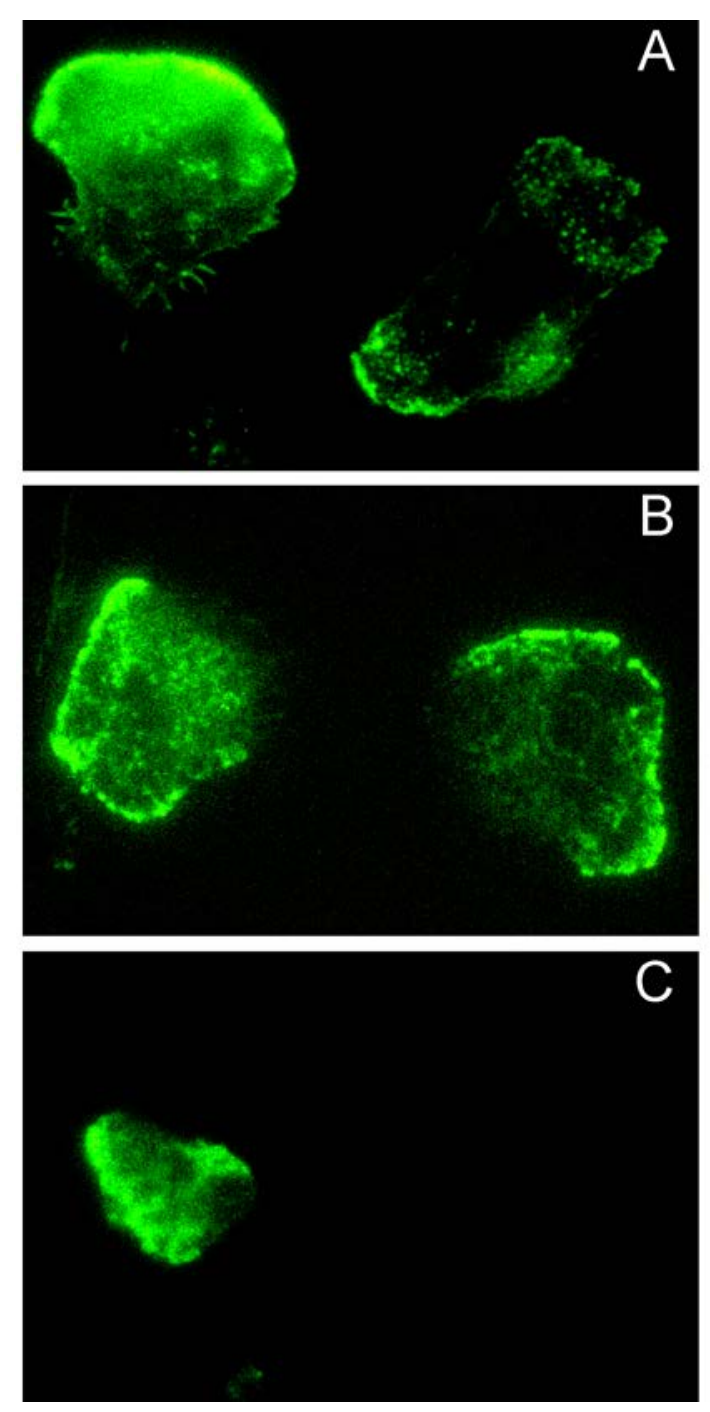
Figure 5

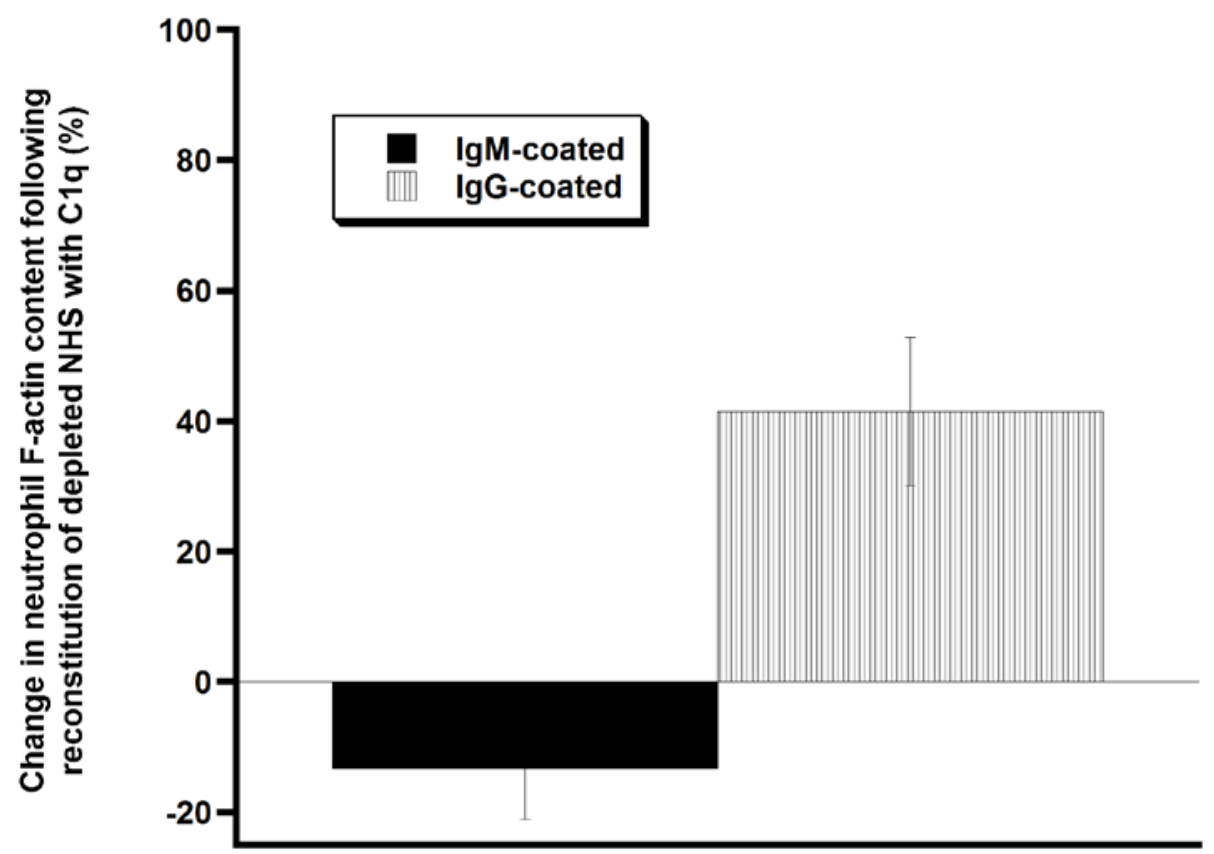

